\title{
Effectiveness and safety of bevacizumab in extensive-disease small cell lung cancer: a systemic review and meta-analysis
}

\author{
Jiaxi He $\mathrm{He}^{1,2,3 \#}$, Hui Pan ${ }^{1,2,3 \#}$, Jianxing He $\mathrm{He}^{1,2,3}$, Shuben $\mathrm{Li}^{1,2,3}$ \\ ${ }^{1}$ Department of Thoracic Surgery, the First Affiliated Hospital of Guangzhou Medical University, Guangzhou, China; ${ }^{2}$ Guangzhou Institute of \\ Respiratory Disease \& China State Key Laboratory of Respiratory Disease, Guangzhou, China; ${ }^{3}$ National Clinical Research Center for Respiratory \\ Disease, Guangzhou, China \\ Contributions: (I) Conception and design: J He, S Li; (II) Administrative support: J He, S Li; (III) Provision of study materials or patients: J He, H \\ Pan; (IV) Collection and assembly of data: J He, H Pan; (V) Data analysis and interpretation: J He; (VI) Manuscript writing: All authors; (VII) Final \\ approval of manuscript: All authors. \\ \#These authors contributed equally to this work. \\ Correspondence to: Shuben Li; Jianxing He. Department of Thoracic Surgery, the First Affiliated Hospital of Guangzhou Medical University, \\ Guangzhou, China. Email: 13500030280@163.com; hejianxing@hotmail.com.
}

\begin{abstract}
Background: Small cell lung cancer (SCLC) is highly invasive and poorly prognostic. The effects of chemotherapy with bevacizumab are promising on other tumors but unclear in extensive-disease SCLC (ED-SCLC). A systemic review and meta-analysis were performed to investigate the efficacy and toxicity in ED-SCLC patients.

Methods: A review of current studies was performed on electronic databases and other sources to identify publications of ED-SCLC patients who received bevacizumab. Endpoints included overall survival (OS), progression-free survival (PFS), objective response rate (ORR), disease control rate (DCR), and complications.

Results: Nine relevant articles with six single-arm and three two-arm studies were identified. Four hundred seventy-six patients were included, of which 368 and 108 were untreated and relapse patients. Most patients were performance status $0-1$ (71.6\%) and male (58.1\%). The comparisons showed CT/bevacizumab slightly prolonged OS $(\mathrm{HR}=0.84)$ but significantly improved PFS (HR =0.74). The ORRs of untreated and relapse patients were $71 \%$ and $19 \%$, though no significant difference was observed than CT/placebo. The most grade 3-4 complication and bevacizumab-associated complications were neutropenia and hypertension, whose rates were $33 \%$ and $6 \%$. Patients who received CT/bevacizumab had a higher hypertension rate than CT/placebo (6\% vs. 2\%). No different complication rate was observed between high and lose dose groups.

Discussion: The present study suggests that bevacizumab in the combination of standard chemotherapy provides better PFS than chemotherapy alone. Although the combined regimen is well-tolerated, no superiority in OS or response rate is observed.
\end{abstract}

Keywords: Small cell lung cancer (SCLC); chemotherapy; bevacizumab; prognosis

Submitted Mar 01, 2021. Accepted for publication Jun 11, 2021.

doi: $10.21037 /$ atm-21-963

View this article at: https://dx.doi.org/10.21037/atm-21-963

\footnotetext{
$\wedge$ ORCID: 0000-0003-2726-6629.
} 


\section{Introduction}

Small cell lung cancer (SCLC) is one of the pathological subtypes of lung cancer characterized as highly invasive, poorly prognostic, and easily metastatic. It currently accounts for $12-15 \%$ of respiratory malignancies $(1,2)$. A more significant proportion of SCLC patients are primarily diagnosed as extensive-disease (ED-SCLC) at presentation, which is defined as the presence of overt metastatic disease by imaging or physical examination.

Platinum-based etoposide regimen (EP) has been recommended as the first-line treatment for ED-SCLC for the last decades (3), which can yield up to $80 \%$ response rate and ten months of survival (4). Other studies reported that the irinotecan/platinum regimen showed a slightly superior or similar effect to the traditional regimen (5-8), which is still unsatisfactory.

Given that vascular endothelial growth factor (VEGF) has been proved to be associated with growth in tumors $(9,10)$ including SCLC $(11,12)$, anti-angiogenic medication is considered a potentially effective treatment in the combination of chemotherapy. Bevacizumab, a humanized monoclonal VEGF antibody, was developed and proved to improve survival in various tumors, including gastric cancer (13), colorectal cancer (14), breast cancer (15), glioblastoma multiforme (16), and non-squamous non-small cell lung cancer (NSCLC). Previous studies on SCLC revealed the ideal survival and response of bevacizumab in both naïve and relapsed SCLC patients (17-22). Besides, some two-arm studies compared the survival outcomes and adverse events (AEs) of SCLC patients who received chemotherapy (CT) with/without bevacizumab (23-25). However, no consensus has been reached on the efficacy of bevacizumab in the combination of CT for treating ED-SCLC.

We, therefore, performed a systemic review and metaanalysis to assess the efficacy and safety of CT/bevacizumab in both untreated and relapse ED-SCLC patients. Besides, the comparisons of survival outcomes and AEs between patients who received CT/bevacizumab and CT/placebo were also analyzed. We present the following article in accordance with the PRISMA reporting checklist (available at https://dx.doi.org/10.21037/atm-21-963).

\section{Methods}

\section{Literature search strategy and selection criteria}

The initial search for potential publications was performed in four electronic bibliography databases, including
MEDLINE, Web of Science, Embase, and Cochrane Central Register of Controlled Trials from the earliest to March 2020. Unpublished studies and data from other sources were also identified for different screening. Search terms were "small cell lung cancer" and synonyms "chemotherapy" and "Bevacizumab". The titles and abstracts of publications were initially screened. The full-text evaluation was performed after the exclusion of irrelevant studies. Both single-arm and two-arm studies were included. Review, abstract, brief report, comment, protocol design, or editorial publications were excluded. Language and species were restricted in English and human only, respectively. Publications with duplicate or unavailable data were eventually excluded from data extraction in further evaluation. Two independent individuals finished the initial search. The senior investigators reviewed the final included publications. A total of 27 publications were eligible for full-text assessment. After further evaluation, 18 candidates were excluded for various reasons, and nine studies were selected for meta-analysis (Figure 1).

\section{Data extraction}

All the data were independently extracted from the articles, tables, figures, and supplements of the publications by two inspectors. The clinical characteristics, numbers of AEs, and time-to-event data, including median overall survival (OS) hazard ratio (HR), progression-free survival (PFS) HR, survival rate, objective response rate (ORR), and disease control rate (DCR) were reviewed and extracted. Some time-to-event data were collected from the Kaplan-Meier curve and its $\mathrm{P}$ value (26). ORR is defined as the proportion of complete response and partial response patients, while DCR is defined as the proportion of complete response, partial response, and stable disease patients. Discrepancies in search and selection would be resolved after the discussion with other group members.

\section{Statistical analysis}

A systemic review and meta-analysis were performed to evaluate the 1-year survival rate, ORR, DCR, and AE incidence. Besides, OS and PFS comparisons between CT/ bevacizumab and CT/placebo were estimated by hazard ratio (HR). AE incidence was evaluated by risk ratio (RR). $\chi^{2}$ tests were conducted to assess the fit of distribution. $\mathrm{I}^{2}$ test was used to estimate the variation across the studies instead of the Q test, whose results were closely related to the 


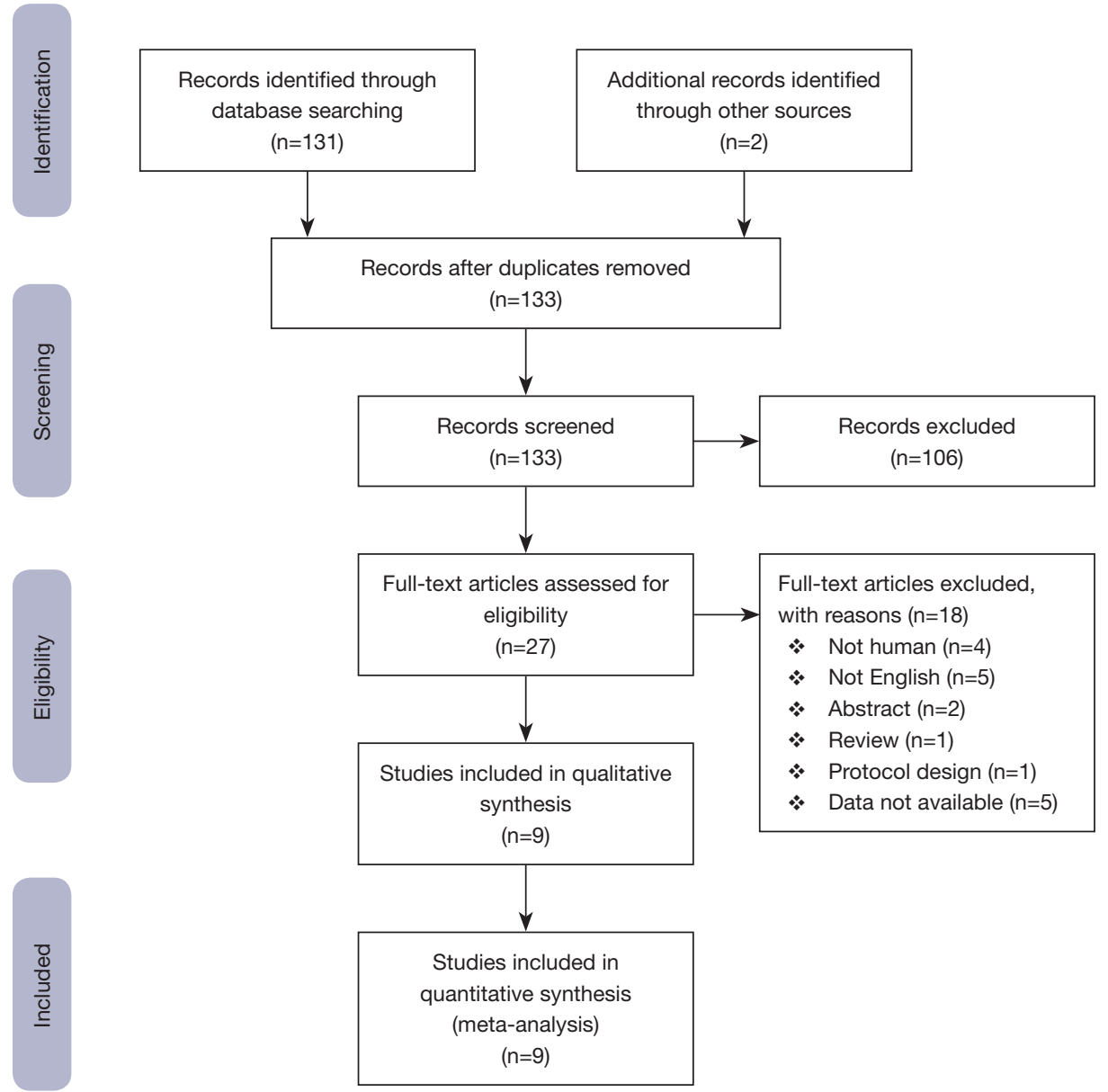

Figure 1 The flow diagram of study selection process.

number of included studies. The formula calculated the $\mathrm{I}^{2}$ : $\mathrm{I}^{2}=100 \% \times(\mathrm{Q}-\mathrm{df}) / \mathrm{Q}$; Q stood for a heterogeneity statistic, and $\mathrm{df}$ was defined as the degree of freedom ( $\mathrm{df}=$ total number of trials -1$)$. The heterogeneity was defined as low $(25-49 \%)$, moderate $(50-74 \%)$, or severe (>75\%). A random-effect analysis model would be used to calculate the endpoints when the heterogeneity was $>50 \%$. Z-test was performed to calculate the p-value, which was two-sided and defined as statistically different when $\mathrm{P}<0.05$. Funnel plots were used to evaluate the publication bias of the included studies. The statistical analysis was conducted via $\mathrm{R}$ (Version 3.6.2).

\section{Results}

\section{Characteristics of enrolled studies}

A total of 133 articles were identified in the initial screening, including 131 from the electronic databases and two from other sources. Of these articles, 106 were excluded as irrelevant studies. The full-text screening was conducted on 27 publications. Nine publications were eventually selected for data extraction and meta-analysis (17-25) (Figure 1). Three studies were two-arm randomized control trials (23-25)' and 6 were single-arm studies (17-22) (Table 1).

A total of 666 patients were included in the cohort. All of them were diagnosed as ED-SCLC, of which 458 previously untreated patients were administered platinum-based doublet regimens, while 108 relapse patients were given topotecan, paclitaxel, or irinotecan. The median ages of patients ranged from 61 to 66 years old. A total of 477 patients received bevacizumab treatment. Most of them (436/477, 71.6\%) had performance status (PS) 0-1. Male patients accounted for a larger proportion in the cohort (277/477, 58.1\%). Referring to bevacizumab dosage, 229 patients in 4 studies received $15 \mathrm{mg} / \mathrm{kg}(17,19,21,24), 81$ in 2 studies received $10 \mathrm{mg} / \mathrm{kg}$ 
Table 1 Overview of the included both single/two-arm studies of ED-SCLC patients received chemotherapy with/without bevacizumab

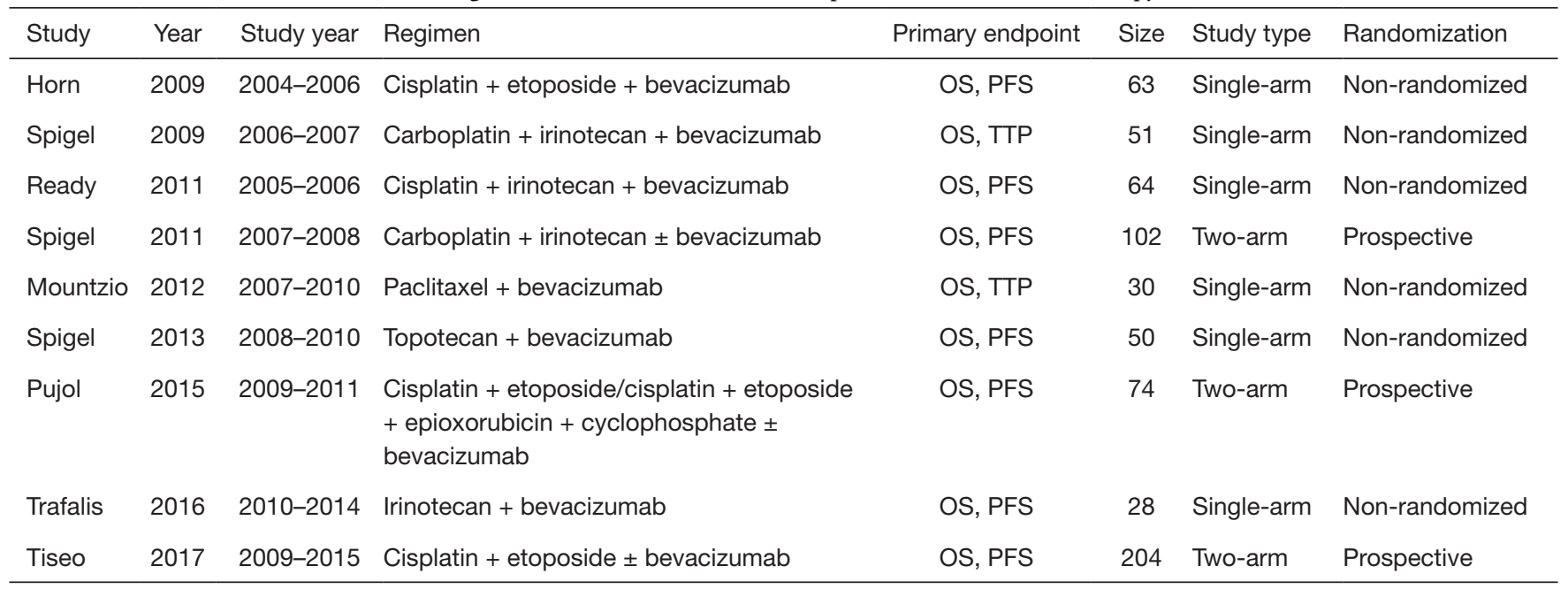

ED-SCLC, extensive-disease small cell lung cancer; OS, overall survival; PFS, progression-free survival.

Table 2 The characteristics of patients received bevacizumab in the included studies

\begin{tabular}{|c|c|c|c|c|c|c|c|c|c|c|}
\hline \multirow[t]{2}{*}{ Study } & \multirow{2}{*}{$\begin{array}{l}\text { Cancer } \\
\text { type }\end{array}$} & \multirow{2}{*}{$\begin{array}{l}\text { Age, median } \\
\text { [range] }\end{array}$} & \multicolumn{2}{|c|}{$\begin{array}{l}\text { Performance } \\
\text { status }\end{array}$} & \multicolumn{2}{|c|}{ Sex } & \multirow{2}{*}{$\begin{array}{c}\text { Bevacizumab } \\
\text { dosage }(\mathrm{mg} / \mathrm{kg})\end{array}$} & \multirow{2}{*}{ Cycles } & \multicolumn{2}{|c|}{ Efficacy } \\
\hline & & & $0-1$ & 2 & Male & Female & & & ORR & DCR \\
\hline Spigel 2009 & Untreated & 66 [46-81] & 51 & 0 & 29 & 22 & 10 & 6 & 43 & 45 \\
\hline Mountzio 2012 & Relapse & 64 [43-82] & 27 & 3 & 27 & 3 & 10 & 4 & 6 & 11 \\
\hline Spigel 2013 & Relapse & 62.5 [28-80] & 46 & 4 & 24 & 26 & 15 & 8 & 8 & 28 \\
\hline Pujol 2015 & Untreated & $61[43-75]$ & 33 & 3 & 25 & 12 & 7.5 & 6 & 32 & 32 \\
\hline
\end{tabular}

ORR, objective response rate; $\mathrm{DCR}$, disease control rate.

$(18,20)$ and 167 patients in 3 studies received $7.5 \mathrm{mg} / \mathrm{kg}$ $(22,23,25)$. Most of the patients in studies received six cycles $(17,19,20,22-25)$ of treatments while others received 4 and 8 cycles in 2 studies $(18,21)$ (Table 2).

\section{Assessment of the efficacy of bevacizumab}

The comparison of CT/bevacizumab versus CT/placebo showed that bevacizumab improved OS of ED-SCLC though it was not significant (HR $=0.84,95 \%$ CI: 0.67-1.06, $\mathrm{P}=0.14$ ). A significantly improved PFS in the bevacizumab group was shown $(\mathrm{HR}=0.74,95 \% \mathrm{CI}: 0.59-0.92, \mathrm{P}=0.007)$ (Figure $2 A$ ). The total 1-year survival rate was $32 \%(95 \%$ CI: $21-44 \%)$. The relapse ED-SCLC patients had a $15 \%$ (95\% CI: 7-30\%) 1-year survival rate, whereas untreated patients had 40\% (95\% CI: 31-50\%) (Figure S1A). The 6-month PFS rates of relapse and untreated patients were $18 \%$ (95\% CI: $7-38 \%$ ) and 51\% (95\% CI: $37-64 \%)$, respectively. The total PFS rate was 38\% (95\% CI: $24-$ $55 \%$ ) (Figure S1B).

Although there was no difference in DCR between the bevacizumab and placebo group $(\mathrm{RR}=0.96,95 \% \mathrm{CI}$ : 

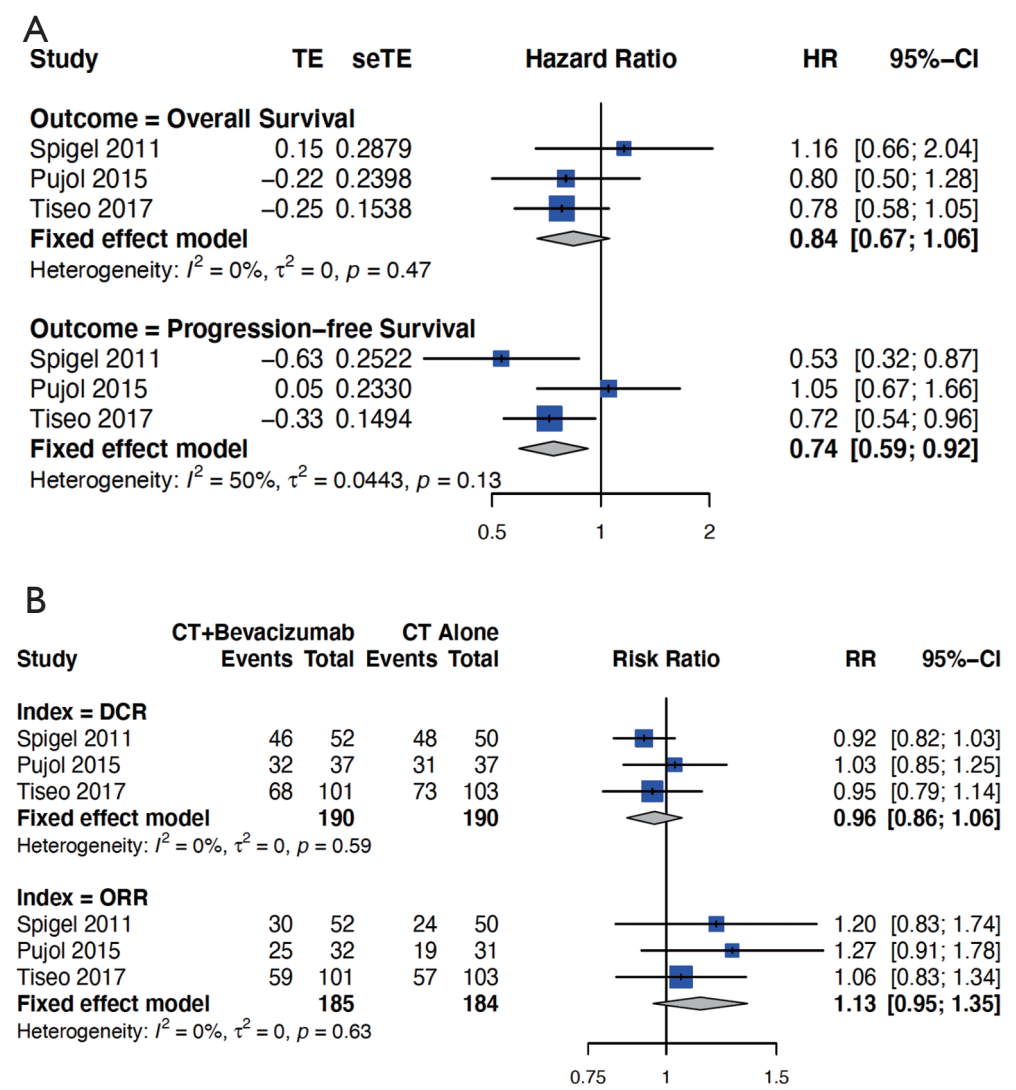

Figure 2 Forest plot of the clinical outcomes of chemotherapy (CT)/bevacizumab versus CT alone in the treatment of extensive-disease small cell lung cancer (ED-SCLC). (A) The estimate hazard ratio (HR) of overall survival (OS) and progression-free survival (PFS) between two groups; (B) the estimate relative risk (RR) of disease-control rate (DCR) and objective-response rate (ORR) between two groups.

0.86-1.06, $\mathrm{P}=0.41)$, the bevacizumab group seemed to have better ORR than the placebo group $(R R=1.13,95 \%$ CI: $0.95-1.35, \mathrm{P}=0.13)$. The overall ORR and DCR were $55 \%$ (95\% CI: $35-73 \%$ ) and 79\% (95\% CI: 67-90\%), respectively (Figure 2B). The relapse patients had lower ORR than the untreated patients (19\% vs. $71 \%)$, while the DCRs of relapse and untreated patients were $63 \%$ and $84 \%$, respectively (Figure S2).

\section{Assessment of the safety of bevacizumab}

Grade 5 AEs were reported in 14 patients in the bevacizumab cohort (14/477, 2.9\%), while 402 cases of Grade 3-4 AEs were reported. In the two-arm studies, no difference of Grade 3-5 AE was observed between bevacizumab and the placebo group. Among AEs, 172 cases of neutropenia and 22 cases of hypertension were the most chemotherapyassociated and bevacizumab-associated complications. No hypertension case was reported in the relapse ED-SCLC patients (Table 3). Patients who received CT/bevacizumab had a higher risk of hypertension than patients who received CT alone ( $R R=3.26,95 \%$ CI: $1.02-10.42, \mathrm{P}<0.01$ ). However, no significant risk of neutropenia was observed between these groups ( $\mathrm{RR}=1.0,95 \% \mathrm{CI}$ : 0.79-1.27) (Figure 3). In detail, the neutropenia rates were $18 \%$ (95\% CI: 9-31\%) in relapse patients and $41 \%$ (95\% CI: 33-50\%) in untreated patients (Figure $4 A$ ), while the total hypertension rate was 6\% (95\% CI: 4-9\%) (Figure 4B). The summary of bias was shown in the funnel plots and the risk of bias plots (Figures S1,S2).

\section{Discussion}

SCLC is an invasive malignancy with a poor prognosis, though it accounts for a small proportion of lung cancer. Surgical treatment with adjuvant chemotherapy or chemotherapy with cranial irradiation has been proved to 
Table 3 Overview of prognosis, disease response and complications of included studies

\begin{tabular}{|c|c|c|c|c|c|c|c|c|}
\hline \multirow{2}{*}{ Study } & \multicolumn{2}{|c|}{ OS } & \multicolumn{2}{|c|}{ PFS } & \multicolumn{4}{|c|}{ Complication } \\
\hline & Median (months) & 12 -month rate & Median (months) & 6-month rate & $3-4$ & 5 & Neutropenia & Hypertensior \\
\hline Horn 2009 & 10.9 & 38.1 & 4.7 & 30.2 & 47 & 2 & 37 & 5 \\
\hline Spigel 2009 & 12.1 & 51 & 9.13 & 76 & 74 & 1 & 20 & 0 \\
\hline Spigel 2011 & 9.4 & 32.4 & 5.45 & 40.3 & 36 & 2 & 18 & 3 \\
\hline Mountzio 2012 & 6.3 & 26.7 & - & 33 & 19 & 0 & 5 & 0 \\
\hline Spigel 2013 & 7.4 & 18 & 4.02 & 22 & 71 & 3 & 14 & 0 \\
\hline Pujol 2015 & 11.1 & 59.5 & 5.3 & 34.4 & 54 & 3 & 15 & 2 \\
\hline
\end{tabular}

OS, overall survival; PFS, progression-free survival.

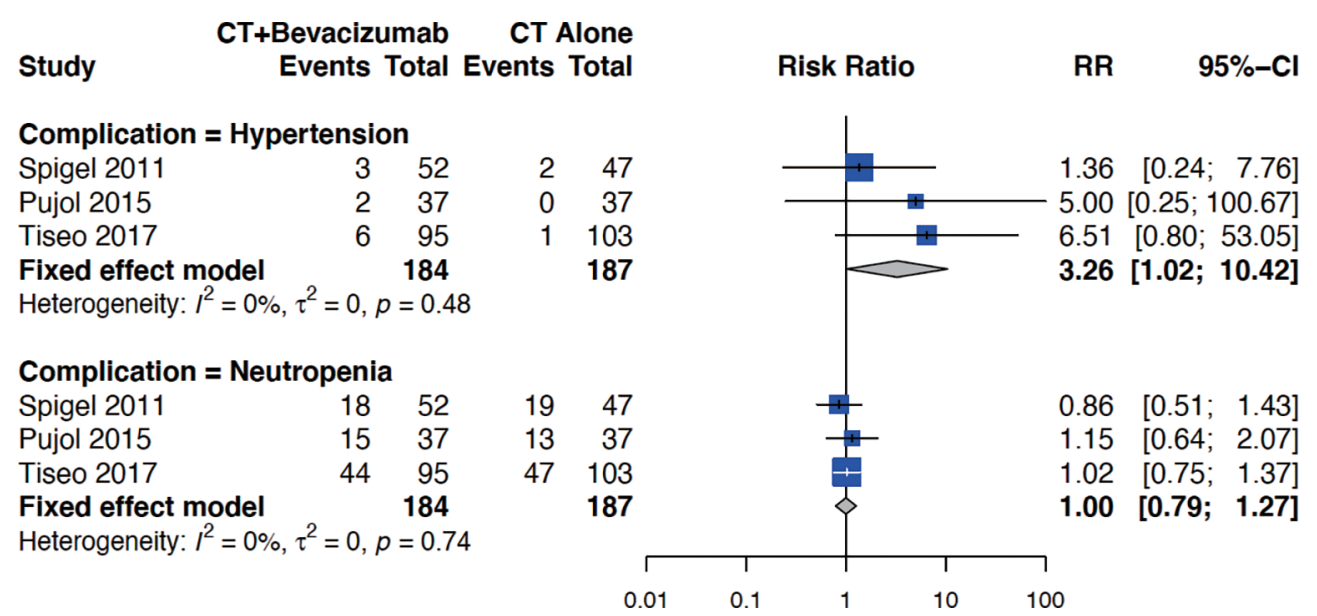

Figure 3 Forest plot of the major complications of chemotherapy (CT)/bevacizumab versus CT alone in the treatment of extensive-disease small cell lung cancer (ED-SCLC).

be effective for limited-disease SCLC (LD-SCLC) (27). Despite the chemotherapy and radiation, ED-SCLC is considered incurable (28). Since the initial recommendation of platinum-based EP, new medications or regimens have not yielded a remarked improvement in ED-SCLC. Antiangiogenic treatment improves prognostic outcomes in various tumors in the combination of standard regimens and becomes a new recommendation in their treatment guidelines. Based on its pronounced effect in non-squamous NSCLC (29,30), several studies have been performed to verify its role in SCLC.
Three two-arm RCTs were included in the studies comparing the efficacy of first-line CT/bevacizumab to CT alone $(23,24,31)$. Although the prognostic advantage of CT/ bevacizumab was not significantly on OS, it could improve PFS. Our study indicated that the total 1-year OS rate and 6-month PFS rates of untreated patients who received CT/ bevacizumab were higher than those who received regular CT (32-34). Two studies were performed to verify the effect of irinotecan/cisplatin versus etoposide/cisplatin. They reported that both arms' median survival ranged from 9.1-10.2 months, while the median time to progression was 4.1-5.6 months $(7,8)$. 
A

Study

Type $=$ Replapse Mountzio 2012 Spigel 2013 Trafalis 2016

Random effects mode

Heterogeneity: $l^{2}=42 \%, p=0.10$

Type $=$ Untreated

Horn 2009

Spigel 2009

Ready 2011

Spigel 2011

Pujol 2015

Tiseo 2017

Random effects mode

Heterogeneity: $I^{2}=62 \%, p=0.0$

Random effects mode

Heterogeneity: $l^{2}=80 \%, p<0.01$

B

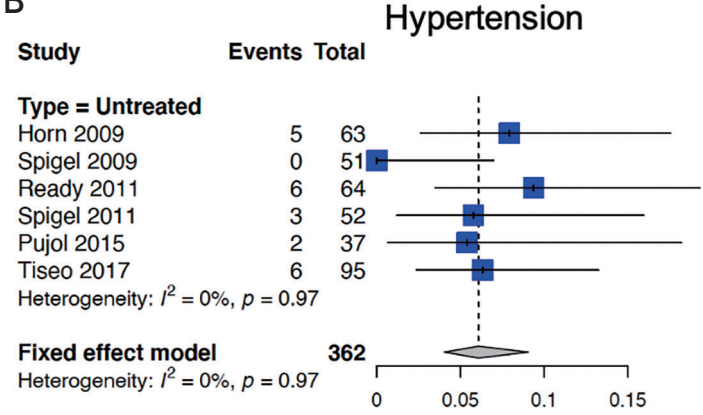

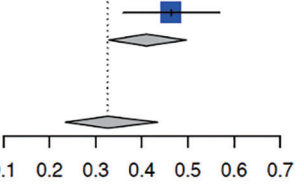

Neutropenia
Proportion $\quad 95 \%-\mathrm{Cl}$

$0.17[0.06 ; 0.35]$

$0.28[0.16 ; 0.42]$

$0.07[0.01 ; 0.24]$

$0.18[0.09 ; 0.31]$

$0.59[0.46 ; 0.71]$

$0.39[0.26 ; 0.54]$

$0.27[0.16 ; 0.39]$

$0.35[0.22 ; 0.49]$

$0.41[0.25 ; 0.58]$

$0.46[0.36 ; 0.57]$

$0.41[0.33 ; 0.50]$

$0.33[0.23 ; 0.43]$ 
tolerable toxicities in ED-SCLC, which were at least not more significant than other cancers.

The bevacizumab dosages in the included studies varied from 7.5 to $15 \mathrm{mg} / \mathrm{kg}$. It is believed that higher dosage is associated with a higher risk of complications. We, therefore, explored the Grade 3-4 hypertension rates among different dosage subgroups. Nevertheless, no significant difference was noticed in the severe hypertension rate between the $15 \mathrm{mg} / \mathrm{kg}$ subgroup and the $7.5 \mathrm{mg} / \mathrm{kg}$ subgroup. No other advantage was observed in the $15 \mathrm{mg} / \mathrm{kg}$ subgroup. These results indicated that higher bevacizumab dosage in ED-SCLC might not bring remark benefit.

The effects of other anti-angiogenic medications on SCLC patients are also investigated. Vandetanib, a tyrosine kinase inhibitor of multiple receptors including VEGFR, EGFR, and RET, was examined in SCLC patients in a phase II RCT. It showed that it could improve PFS of SCLC patients and significantly prolong OS in LD-SCLC. Unfortunately, ED-SCLC patients in the vandetanib group had shorter survival than the placebo group (39). Sunitinib, another multitarget tyrosine kinase inhibitor, was administered to ED-SCLC patients for maintenance therapy. Both improved OS and PFS were observed in this study, which was up to 3.7 and 9 months, respectively (40). Some researchers tried to verify the effect of thalidomide in SCLC, but no benefit from either PFS or OS was observed in the studies $(41,42)$.

On the other hand, thalidomide was seldom used because of its potential teratogenic effect (43). Only a few studies compared CT/bevacizumab to CT alone in SCLC patients. We, therefore, performed both comparative and singlearm integrated meta-analysis to investigate the efficacy and safety of the additional administration of bevacizumab. A total of three comparative studies were eligible for analysis, which might be inconclusive because of few candidates.

The current recommended standard treatment for EDSCLC is the combination of platinum-based chemotherapy and atezolizumab, which showed significant improvement compared to the chemotherapy alone. Meanwhile, the bevacizumab plus atezolizumab have been proved to yield better survival outcomes in other tumors (e.g., hepatocellular carcinoma, renal cell carcinoma) than monotherapy $(44,45)$. The roles of anti-angiogenesis treatment with immunotherapy are worth verifying in EDSCLC. A phase II single-arm study of carboplatin plus etoposide with bevacizumab and atezolizumab in EDSCLC patients is ongoing in Europe (NCT04730999).
Besides, another phase III randomized study of bevacizumab combined with carboplatin or cisplatin + etoposide + atezolizumab compared with carboplatin or cisplatin + etoposide + atezolizumab in untreated ED-SCLC patients is recruiting patients in Japan (JapicCTI-195034). These trials would provide some new ideas for using bevacizumab in the presence of immunotherapy in SCLC.

In conclusion, the effects of anti-angiogenic medication in SCLC patients are not completely clear. The present study suggests that bevacizumab in the combination of standard chemotherapy provides similar OS and slightly improved PFS than chemotherapy alone. Although the response rate is not remarkedly superior, this regimen is well tolerable. It also indicates that $7.5 \mathrm{mg} / \mathrm{kg}$ dosage of bevacizumab provides a similar effect to ED-SCLC patients with a lower risk of bevacizumab-associated complication. Further investigations on the dosage and cost-effectiveness are warranted to figure out its application. The roles of anti-angiogenesis treatment in the combination with IO is also expected to be verified.

\section{Acknowledgments}

Funding: None.

\section{Footnote}

Reporting Checklist: The authors have completed the PRISMA reporting checklist. Available at https://dx.doi. org/10.21037/atm-21-963

Peer Review File: Available at https://dx.doi.org/10.21037/ atm-21-963

Conflicts of Interest: All authors have completed the ICMJE uniform disclosure form (available at https://dx.doi. org/10.21037/atm-21-963). JH serves as an editor-inchief of Annals of Translational Medicine from Jun 2019 to May 2024. JH serves as an unpaid section editor of Annals of Translational Medicine from Jan 2021 to Dec 2021. The other authors have no conflicts of interest to declare.

Ethical Statement: The authors are accountable for all aspects of the work in ensuring that questions related to the accuracy or integrity of any part of the work are appropriately investigated and resolved.

Open Access Statement: This is an Open Access article 
distributed in accordance with the Creative Commons Attribution-NonCommercial-NoDerivs 4.0 International License (CC BY-NC-ND 4.0), which permits the noncommercial replication and distribution of the article with the strict proviso that no changes or edits are made and the original work is properly cited (including links to both the formal publication through the relevant DOI and the license). See: https://creativecommons.org/licenses/by-nc-nd/4.0/.

\section{References}

1. Govindan R, Page N, Morgensztern D, et al. Changing epidemiology of small-cell lung cancer in the United States over the last 30 years: analysis of the surveillance, epidemiologic, and end results database. J Clin Oncol 2006;24:4539-44.

2. Jemal A, Siegel R, Ward E, et al. Cancer statistics, 2008. CA Cancer J Clin 2008;58:71-96.

3. Früh M, De Ruysscher D, Popat S, et al. Small-cell lung cancer (SCLC): ESMO Clinical Practice Guidelines for diagnosis, treatment and follow-up. Ann Oncol 2013;24 Suppl 6:vi99-105.

4. Chute JP, Chen T, Feigal E, et al. Twenty years of phase III trials for patients with extensive-stage smallcell lung cancer: perceptible progress. J Clin Oncol 1999;17:1794-801.

5. Liu ZL, Wang B, Liu JZ, et al. Irinotecan plus cisplatin compared with etoposide plus cisplatin in patients with previously untreated extensive-stage small cell lung cancer: A meta-analysis. J Cancer Res Ther 2018;14:S1076-83.

6. Noda K, Nishiwaki Y, Kawahara M, et al. Irinotecan plus cisplatin compared with etoposide plus cisplatin for extensive small-cell lung cancer. N Engl J Med 2002;346:85-91

7. Lara PN Jr, Natale R, Crowley J, et al. Phase III trial of irinotecan/cisplatin compared with etoposide/cisplatin in extensive-stage small-cell lung cancer: clinical and pharmacogenomic results from SWOG S0124. J Clin Oncol 2009;27:2530-5.

8. Hanna N, Bunn PA Jr, Langer C, et al. Randomized phase III trial comparing irinotecan/cisplatin with etoposide/ cisplatin in patients with previously untreated extensivestage disease small-cell lung cancer. J Clin Oncol 2006;24:2038-43.

9. Ferrara N. Role of vascular endothelial growth factor in physiologic and pathologic angiogenesis: therapeutic implications. Semin Oncol 2002;29:10-4.

10. Dvorak HF. Vascular permeability factor/vascular endothelial growth factor: a critical cytokine in tumor angiogenesis and a potential target for diagnosis and therapy. J Clin Oncol 2002;20:4368-80.

11. Salven P, Ruotsalainen T, Mattson K, et al. High pretreatment serum level of vascular endothelial growth factor (VEGF) is associated with poor outcome in small-cell lung cancer. Int J Cancer 1998;79:144-6.

12. Tanno S, Ohsaki Y, Nakanishi K, et al. Human small cell lung cancer cells express functional VEGF receptors, VEGFR-2 and VEGFR-3. Lung Cancer 2004;46:11-9.

13. Shah MA, Ramanathan RK, Ilson DH, et al. Multicenter phase II study of irinotecan, cisplatin, and bevacizumab in patients with metastatic gastric or gastroesophageal junction adenocarcinoma. J Clin Oncol 2006;24:5201-6.

14. Hurwitz H, Fehrenbacher L, Novotny W, et al. Bevacizumab plus irinotecan, fluorouracil, and leucovorin for metastatic colorectal cancer. $\mathrm{N}$ Engl J Med 2004;350:2335-42.

15. Gray R, Bhattacharya S, Bowden C, et al. Independent review of E2100: a phase III trial of bevacizumab plus paclitaxel versus paclitaxel in women with metastatic breast cancer. J Clin Oncol 2009;27:4966-72.

16. Friedman HS, Prados MD, Wen PY, et al. Bevacizumab alone and in combination with irinotecan in recurrent glioblastoma. J Clin Oncol 2009;27:4733-40.

17. Horn L, Dahlberg SE, Sandler AB, et al. Phase II study of cisplatin plus etoposide and bevacizumab for previously untreated, extensive-stage small-cell lung cancer: Eastern Cooperative Oncology Group Study E3501. J Clin Oncol 2009;27:6006-11.

18. Mountzios G, Emmanouilidis C, Vardakis N, et al. Paclitaxel plus bevacizumab in patients with chemoresistant relapsed small cell lung cancer as salvage treatment: a phase II multicenter study of the Hellenic Oncology Research Group. Lung Cancer 2012;77:146-50.

19. Ready NE, Dudek AZ, Pang HH, et al. Cisplatin, irinotecan, and bevacizumab for untreated extensive-stage small-cell lung cancer: CALGB 30306, a phase II study. J Clin Oncol 2011;29:4436-41.

20. Spigel DR, Greco FA, Zubkus JD, et al. Phase II trial of irinotecan, carboplatin, and bevacizumab in the treatment of patients with extensive-stage small-cell lung cancer. J Thorac Oncol 2009;4:1555-60.

21. Spigel DR, Waterhouse DM, Lane S, et al. Efficacy and safety of oral topotecan and bevacizumab combination as second-line treatment for relapsed small-cell lung cancer: an open-label multicenter single-arm phase II study. Clin Lung Cancer 2013;14:356-63. 
22. Trafalis DT, Alifieris C, Stathopoulos GP, et al. Phase II study of bevacizumab plus irinotecan on the treatment of relapsed resistant small cell lung cancer. Cancer Chemother Pharmacol 2016;77:713-22.

23. Pujol JL, Lavole A, Quoix E, et al. Randomized phase II-III study of bevacizumab in combination with chemotherapy in previously untreated extensive small-cell lung cancer: results from the IFCT-0802 trial†. Ann Oncol 2015;26:908-14.

24. Spigel DR, Townley PM, Waterhouse DM, et al. Randomized phase II study of bevacizumab in combination with chemotherapy in previously untreated extensive-stage small-cell lung cancer: results from the SALUTE trial. J Clin Oncol 2011;29:2215-22.

25. Tiseo M, Boni L, Ambrosio F, et al. Italian, Multicenter, Phase III, Randomized Study of Cisplatin Plus Etoposide With or Without Bevacizumab as First-Line Treatment in Extensive-Disease Small-Cell Lung Cancer: The GOIRCAIFA FARM6PMFJM Trial. J Clin Oncol 2017;35:1281-7.

26. Parmar MK, Torri V, Stewart L. Extracting summary statistics to perform meta-analyses of the published literature for survival endpoints. Stat Med 1998;17:2815-34.

27. Yang CF, Chan DY, Speicher PJ, et al. Role of Adjuvant Therapy in a Population-Based Cohort of Patients With Early-Stage Small-Cell Lung Cancer. J Clin Oncol 2016;34:1057-64.

28. Murray N, Turrisi AT 3rd. A review of first-line treatment for small-cell lung cancer. J Thorac Oncol 2006;1:270-8.

29. Saito H, Fukuhara T, Furuya N, et al. Erlotinib plus bevacizumab versus erlotinib alone in patients with EGFR-positive advanced non-squamous non-small-cell lung cancer (NEJ026): interim analysis of an open-label, randomised, multicentre, phase 3 trial. Lancet Oncol 2019;20:625-35.

30. Wakelee HA, Dahlberg SE, Keller SM, et al. Adjuvant chemotherapy with or without bevacizumab in patients with resected non-small-cell lung cancer (E1505): an openlabel, multicentre, randomised, phase 3 trial. Lancet Oncol 2017;18:1610-23.

31. Tiseo M, Boni L, Ambrosio F, et al. Italian multicenter phase III randomized study of cisplatin-etoposide with or without bevacizumab as first-line treatment in extensive stage small cell lung cancer: treatment rationale and protocol design of the GOIRC-AIFA FARM6PMFJM trial. Clin Lung Cancer 2015;16:67-70.

32. Fukuoka M, Furuse K, Saijo N, et al. Randomized trial of cyclophosphamide, doxorubicin, and vincristine versus cisplatin and etoposide versus alternation of these regimens in small-cell lung cancer. J Natl Cancer Inst 1991;83:855-61.

33. Wolf M, Havemann K, Holle R, et al. Cisplatin/etoposide versus ifosfamide/etoposide combination chemotherapy in small-cell lung cancer: a multicenter German randomized trial. J Clin Oncol 1987;5:1880-9.

34. Roth BJ, Johnson DH, Einhorn LH, et al. Randomized study of cyclophosphamide, doxorubicin, and vincristine versus etoposide and cisplatin versus alternation of these two regimens in extensive small-cell lung cancer: a phase III trial of the Southeastern Cancer Study Group. J Clin Oncol 1992;10:282-91.

35. Eckardt JR, von Pawel J, Papai Z, et al. Open-label, multicenter, randomized, phase III study comparing oral topotecan/cisplatin versus etoposide/cisplatin as treatment for chemotherapy-naive patients with extensive-disease small-cell lung cancer. J Clin Oncol 2006;24:2044-51.

36. O'Brien ME, Ciuleanu TE, Tsekov H, et al. Phase III trial comparing supportive care alone with supportive care with oral topotecan in patients with relapsed small-cell lung cancer. J Clin Oncol 2006;24:5441-7.

37. Eckardt JR, von Pawel J, Pujol JL, et al. Phase III study of oral compared with intravenous topotecan as secondline therapy in small-cell lung cancer. J Clin Oncol 2007;25:2086-92.

38. Sandler A, Gray R, Perry MC, et al. Paclitaxel-carboplatin alone or with bevacizumab for non-small-cell lung cancer. N Engl J Med 2006;355:2542-50.

39. Arnold AM, Seymour L, Smylie M, et al. Phase II study of vandetanib or placebo in small-cell lung cancer patients after complete or partial response to induction chemotherapy with or without radiation therapy: National Cancer Institute of Canada Clinical Trials Group Study BR.20. J Clin Oncol 2007;25:4278-84.

40. Ready NE, Pang HH, Gu L, et al. Chemotherapy With or Without Maintenance Sunitinib for Untreated ExtensiveStage Small-Cell Lung Cancer: A Randomized, DoubleBlind, Placebo-Controlled Phase II Study-CALGB 30504 (Alliance). J Clin Oncol 2015;33:1660-5.

41. Pujol JL, Breton JL, Gervais R, et al. Phase III doubleblind, placebo-controlled study of thalidomide in extensive-disease small-cell lung cancer after response to chemotherapy: an intergroup study FNCLCC cleo04 IFCT 00-01. J Clin Oncol 2007;25:3945-51.

42. Lee SM, Woll PJ, Rudd R, et al. Anti-angiogenic therapy using thalidomide combined with chemotherapy in small cell lung cancer: a randomized, double-blind, placebocontrolled trial. J Natl Cancer Inst 2009;101:1049-57. 
43. Stephens TD, Bunde CJ, Fillmore BJ. Mechanism of action in thalidomide teratogenesis. Biochem Pharmacol 2000;59:1489-99.

44. Finn RS, Qin S, Ikeda M, et al. Atezolizumab plus Bevacizumab in Unresectable Hepatocellular Carcinoma. N Engl J Med 2020;382:1894-905.

Cite this article as: $\mathrm{He} \mathrm{J}$, Pan $\mathrm{H}, \mathrm{He} \mathrm{J}$, Li S. Effectiveness and safety of bevacizumab in extensive-disease small cell lung cancer: a systemic review and meta-analysis. Ann Transl Med 2021;9(16):1285. doi: 10.21037/atm-21-963
45. Rini BI, Powles T, Atkins MB, et al. Atezolizumab plus bevacizumab versus sunitinib in patients with previously untreated metastatic renal cell carcinoma (IMmotion151): a multicentre, open-label, phase 3, randomised controlled trial. Lancet 2019;393:2404-15. 
A

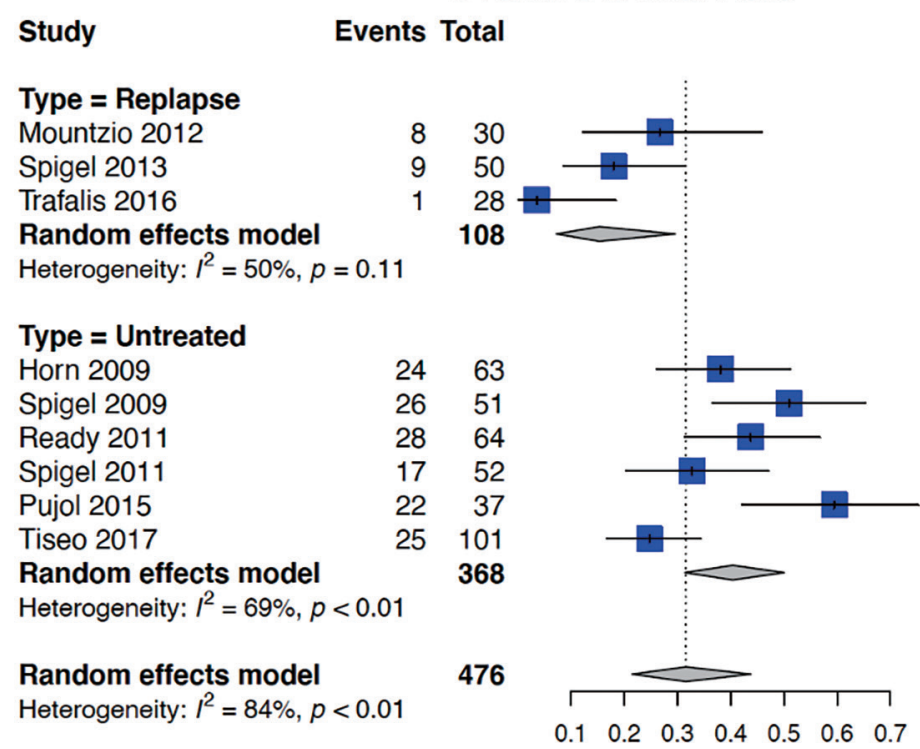

Proportion $\quad 95 \%-\mathrm{Cl}$

$0.27[0.12 ; 0.46]$

$0.18[0.09 ; 0.31]$

$0.04[0.00 ; 0.18]$

$0.15[0.07 ; 0.30]$

$0.38[0.26 ; 0.51]$

$0.51[0.37 ; 0.65]$

$0.44[0.31 ; 0.57]$

$0.33[0.20 ; 0.47]$

$0.59[0.42 ; 0.75]$

$0.25[0.17 ; 0.34]$

$0.40[0.31 ; 0.50]$

$0.32[0.21 ; 0.44]$

B

Progression-free Survival Rate

Study Events Total

Proportion $\quad 95 \%-\mathrm{Cl}$

Type $=$ Relapse Mountzio 2012

Spigel 2013

Trafalis 2016

Random effects model

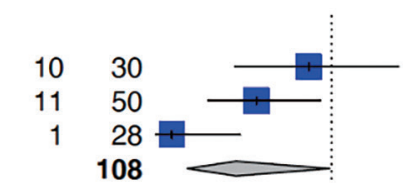

Heterogeneity: $I^{2}=72 \%, p=0.05$

Type $=$ Untreated

Horn 2009

Spigel 2009

Ready 2011

Spigel 2011

Pujol 2015

Tiseo 2017

Random effects model

Heterogeneity: $I^{2}=84 \%, p<0.01$

Random effects model

Heterogeneity: $I^{2}=91 \%, p<0.01$

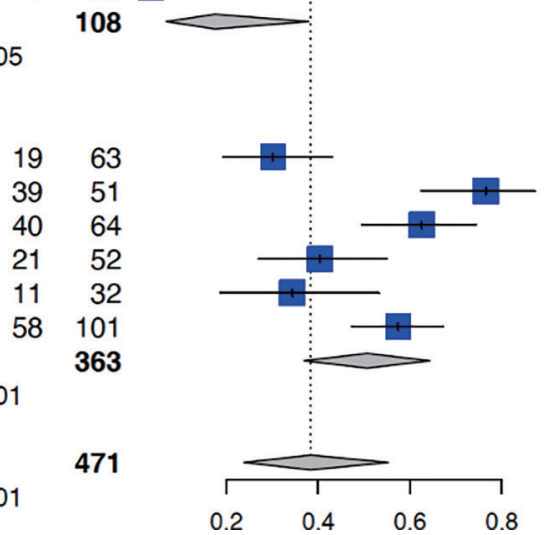

$0.33[0.17 ; 0.53]$

$0.22[0.12 ; 0.36]$

$0.04[0.00 ; 0.18]$

$0.18[0.07 ; 0.38]$

$0.30[0.19 ; 0.43]$

$0.76[0.63 ; 0.87]$

$0.62[0.50 ; 0.74]$

$0.40[0.27 ; 0.55]$

$0.34[0.19 ; 0.53]$

$0.57[0.47 ; 0.67]$

$0.51[0.37 ; 0.64]$

$0.38[0.24 ; 0.55]$

Figure S1 Forest plot of the summarized clinical outcomes of chemotherapy (CT)/bevacizumab in the treatment of extensive-disease small cell lung cancer (ED-SCLC) including the untreated and the relapsed patients. (A) The summarized overall survival (OS) of CT/ bevacizumab group; (B) the summarized progression-free survival (PFS) of CT/bevacizumab group. 
Proportion $\quad 95 \%-\mathrm{Cl}$

Type $=$ Replapse

Mountzio 2012

Spigel 2013

Trafalis 2016

Random effects model

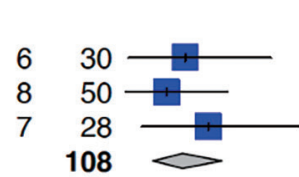

Heterogeneity: $l^{2}=0 \%, p=0.63$

Type $=$ Untreated

Horn 2009

Spigel 2009

Ready 2011

Spigel 2011

Pujol 2015

Tiseo 2017

Random effects model

Heterogeneity: $I^{2}=75 \%, p<0.01$

Random effects model

Heterogeneity: $I^{2}=93 \%, p<0.01$

B

Disease Control Rate

\section{Study}

Type $=$ Replapse Mountzio 2012

Spigel 2013

Trafalis 2016

Random effects model

Heterogeneity: $I^{2}=86 \%, p<0.01$

Type $=$ Untreated

Horn 2009

Spigel 2009

Ready 2011

Spigel 2011

Pujol 2015

Tiseo 2017

Random effects model

Heterogeneity: $I^{2}=68 \%, p<0.01$

Random effects model

Heterogeneity: $I^{2}=86 \%, p<0.01$
Events Total

$\begin{array}{rr}11 & 30 \\ 28 & 50 \\ 25 & 28 \\ & 108 \\ 01 & \end{array}$

Proportion $\quad 95 \%-\mathrm{Cl}$

$0.37[0.20 ; 0.56]$

$0.56[0.41 ; 0.70]$

$0.89[0.72 ; 0.98]$

$0.63[0.34 ; 0.86]$

$0.79[0.67 ; 0.89]$

$0.88[0.76 ; 0.96]$

$0.92[0.83 ; 0.97]$

$0.88[0.77 ; 0.96]$

$0.86[0.71 ; 0.95]$

$0.67[0.57 ; 0.76]$

$0.84[0.76 ; 0.90]$

$0.79[0.67 ; 0.88]$

Figure S2 Forest plot of the summarized clinical outcomes of chemotherapy (CT)/bevacizumab in the treatment of extensive-disease small cell lung cancer (ED-SCLC) including the untreated and the relapsed patients. (A) The summarized objective response rate (ORR) of CT/ bevacizumab group; (B) the summarized disease control rate (DCR) of CT/bevacizumab group. 